\title{
1
}

\section{The Cooperation Imperative}

\author{
Cary Krosinsky
}

Asia is half of the world's economy (UNCTAD 2019), home to over twothirds of the world's largest cities, and China is the dominant player in the region.

The Financial Times recently declared without hesitation that "The Asian Century is set to begin" (Financial Times 2019). Few doubts remain that this will come to pass, with China only likely to become more influential on the back of its recent economic rise during the last 40 years. ${ }^{1}$

The implications of this economic balance between East and West may not sink in quickly and are too often viewed in a largely competitive light.

It would be easy then for a tremendous opportunity to be lost, as surrounds the possibility for renewed cooperation and the potential power of combined inspiration and innovation that can help solve the world's most significant environmental, social and economic challenges. At stake is nothing less than the survival of the world as we know it. And this has all become only more important given the outbreak of the novel coronavirus.

All economies need to find ways to flourish without doing further damage to our planet and its endangered ecosystems and increasingly carbon-intensive atmosphere. Although global politicians at times avoid these challenges, or actively set policy courses away from what is necessary, within the scientific community the imperative to take action is crystal clear, as is the global mandate before us all, and that is:

\footnotetext{
${ }^{1}$ China is now a clear second in terms of nominal global GDP (World Bank 2018), is close to being on par with the US in terms of purchasing power parity (ibid.), is three times larger in size than Japan, is the second largest country in Asia, and China has been Asia’s main trading partner in recent times with a long and interconnected history of this being the case (South China Morning Post 2018).
} 
If we really care about solving the global climate change challenge before us all, the need to cooperate with China is the new imperative of our times.

Whether cooperation will be challenging or not, in fact it's often the harder things in life that are most worth pursuing.

It's impossible to see a way forward where we successfully solve for climate change, let alone some of the other more pressing societal issues of the day, without China's direct engagement and involvement. The rest of Asia also needs a successful, positive transition across environmental and societal challenges, one that helps usher in a lower-carbon emissions trajectory for the world, and China's success at this would help them later assist the rest of Asia. Such successful transitions only occur at a necessary pace during conditions of economic vibrancy, making cooperation an essential and new modern-day paradigm.

Former Secretary of State John Kerry was one of the strategic architects of the Paris Agreement and led bilateral negotiations that preceded the establishment of this agreement between the US and China (Axios 2019). While the Paris Agreement itself is insufficient for solving climate change (Reuters 2019), it was the first sign that global cooperation on climate was possible, and serves as a good example as to how future collaboration and cooperation can and must occur. Kerry recently made clear (Yale 2019) that he was aware of dozens of developing world countries which, if the West invested in them along with China, could accelerate each of their own low-carbon energy transitions together as another example of potentially useful future cooperation.

Here in the US, global cooperation is a bipartisan imperative and one that should not be political even if it often is in practice. This is increasingly recognized and called for by leading investors, such as Ray Dalio of Bridgewater Associates, who said "There is a lot to respect about the Chinese culture and approach that led to its remarkable accomplishments. We would do well to learn from each other, cooperate and compete to bring each other up rather than to tear each other down. China is a place we need to continue to evolve with and invest in" (Dalio 2019).

Hank Paulson, former US Secretary of the Treasury for Republican President George W. Bush, helped launch the US China Green Fund (Chap. 12) as part of his extended relationship with China. Former California governor Jerry Brown recently helped create the California China Climate Initiative at the University of California, Berkeley, to develop and scale innovations related to climate change, and politicians across parties such as Michael Bloomberg, John Kasich, Joe Biden and former Secretary of State Henry Kissinger also often reflect on the imperative for better relations and more financial cooperation. 
Recent Nobel Prize winner and Yale economist William Nordhaus developed the idea of Carbon Country Clubs, the concept being for the US and China to agree on a carbon price, with tariffs imposed on those who don't choose to participate, which would make this an economic imperative as well for countries that choose not to participate (Nordhaus 2015).

None of this will be easy, but it's time to stare reality directly in the eye and get on with what we need to do together to achieve a necessary low-carbon future. This includes strategies that pertain to the future of state-owned enterprises and the fact that public companies in Asia often have governance considerations that would otherwise be unacceptable to Western investors (see Appendix A for a further synopsis on Sustainable Investing and related strategies and terms commonly used).

There is also insufficient data and transparency that might otherwise be useful and required across all of the developing world, those often being wealthy family-dominated economies, but we must get on with finding and implementing solutions. If we don't get on this at once we won't come close to achieving a necessary transition, particularly as pertains to creating measurably fewer greenhouse gas emissions annually on a global basis. "Bending the curve" on annual carbon emissions won't be easy but it will be the only way to ensure future economic success. The entirety of climate science now makes this abundantly clear (see Appendix B for links to brief climate change explainers).

The need to help Asia with its low-carbon transition becomes even clearer when one considers that China uses half of the world's coal, and that coal represents roughly $40 \%$ of the global carbon footprint (Stanford Woods Institute for the Environment 2019), and that Asia's carbon emissions are expected to represent something like 50\% of the global total as early as 2030 (EIA 2016).

Asia's rising middle class understandably demands lifestyles long enjoyed in the West, and it's not only India and China; the ASEAN region is expected to become increasingly economically relevant, anticipated to become the fourth largest economy combined by 2050 after China, India and the US (US-ASEAN Business Council 2019).

In developing countries, transitions away from coal are particularly challenging. ASEAN countries such as Indonesia have understandable societal demands from their poorer populations, making it particularly difficult financially to convert away from the cheapest energy sources. This dynamic makes a full, global, low-carbon transition even harder to achieve at the necessary pace and scale, and it is therefore of the essence that this receives more focus, specific planning and coordination. Rather than ignoring this, we need to dive in and find the best way to enable this transition together with Asia. 
There is increasingly disturbing tangible evidence at hand of where we are heading as a global society. Accelerating incidents of fire and rapidly melting glaciers in Asia that provide essential drinking water to vast populations are only two examples helping to clarify that a low-carbon transition is of the essence to avoid a series of global calamities. Such disasters would be impossible for anyone to avoid, including the medium-term likelihood of billions more climate refugees, further significantly degraded arable land and forests, projected further incidents of human disease outbreaks, depleted ocean fisheries and the loss of critically important biodiversity.

Global economic vibrancy in such a medium-term future is impossible to imagine, and the only way out is to cooperate at global scale as quickly as possible to avoid financial collapse, while creating robust economies which can thrive together. The establishment of successful low-carbon transitions, which require economic vibrancy in order to occur, would create a self-supporting positive dynamic, arguably the only real possibility of a vibrant economic future.

Successful sustainable transitions also provide better immediate realities on the ground for those being affected directly today, whether in cities across Asia suffering from the ill health effects of significant levels of PM2.5, or for the ongoing survival of the oceans now absorbing unsupportable levels of increased heat, or for minimizing the potentially very high financial and human cost of not only billions of climate refugees, but the overall health and well-being of people everywhere.

We can still avoid all of this, but only if we get rapidly on the case.

The essential transition needs to be fully implemented globally across financial and economic systems, specifically in the form of lower carbon transportation, through more efficient industrial processes, buildings and waste streams, and especially through the increased generation of electricity from lower-carbon sources, as well as through sustainable agriculture techniques and related innovations, while also minimizing deforestation (IPCC 2014).

This type of systemic approach turns out to also be the best way forward for regional economic success, especially for countries that choose to lead the way in developing new technologies that enable this transition, and on this front the race is on (Chap. 3), and no country has arguably been as all-in on this transition as China (Chaps. 9 and 19).

There are other present-day economic realities where more cooperation would be helpful, including as regards levels of slavery which continue to be embedded at unacceptable levels within supply chains of large companies producing much of what we globally consume.

Economically suffering US farmers have also been unable to sell easily in Chinese markets during the recent trade war. Such Chinese markets include 
what is now the world's largest middle class (China Daily 2017) willing to pay more for food they can trust.

Sitting on the outside and complaining about problems or exacerbating tensions isn't nearly as effective as building trusted relationships and working together to find mutually beneficial solutions and better economic conditions.

The race is also on as pertains to the creation of all sorts of new, enabling technologies such as 5G and 6G to follow, through fintech, as well as blockchain, battery storage, new forms of energy (Chap. 3) and even carbon capture and sequestration, and there are also opportunities for more creative methods such as open global innovation and the creation and use of new materials (Krosinsky et al. 2018).

Winners will thrive within sectors, and some sectors will continue to transform at the expense of technologies that are no longer necessary, including ongoing transitions away from coal and oil such as results from research that Carbon Tracker Initiative and others continue to demonstrate, and thus investing in the status quo comes with its own new risks to now be fully considered.

The death of traditional industries such as the newspaper and music industry is likely just a harbinger of what is to follow across automobile and truck manufacturing, within shipping, and as regards the methods of production of consumer goods and the continuing use of plastics.

Investors thinking these transitions won't occur could well be caught out in the near future (for more on sustainable investing, see Appendix A), and as we concluded in our first book, Sustainable Investing: The Art of Long Term Performance (Krosinsky et al. 2008), markets need winners and losers, so actually not everyone needs to be on board for the transition to be successful.

Just enough investment, along with global companies applying better strategies around the world, supported by the right policies, can help tip the scale of the global economy in a more urgent, necessary direction.

But perhaps more than anything, we need more people who want this transition to occur, and maybe hardest of all will be changing the ongoing decisions of the average person. People make up roughly two-thirds of the global footprint when one considers choices of transportation, regional energy mixes and the ongoing consumption of food and goods.

The average voter in many countries decides who sets or doesn't set supportive policies which can make or break the speed of the transition. Especially in the US, the collective voice of individual investors and voters in aggregate is a critical determinant in this regard.

The good news is that in China, none of this is an issue.

The Chinese government is on the hook to deliver better results to justify its keeping control, and therefore wants and arguably needs to meet the increasing 
demands of its middle class, including the air, food and water quality conditions often taken for granted in more developed parts of the world.

Helping China with its successful transition becomes a necessary paradigm for making global progress on climate change and can also become an important case study for the world to learn from. Any alternative scenario makes solving the global climate challenge that much harder and that much less likely to achieve.

Consumption in the West, outsourced over time to China and Asia more generally, is also at least partly responsible for the local environmental degradation which resulted as a side effect, and hence we bear some responsibility for ensuring this gets resolved.

Fortunately, consumer tastes are also starting to change, with companies such as Tesla and Beyond Meat emerging as chic and financially successful, specifically due to their being seen as providing better solutions to transportation needs and the production of food respectively, as specifically connects to this necessary transition. Increasingly, people also want renewable energy, and over time more people are likely to want sustainable electricity as renewables continue to emerge as the least costly option.

The global unicorns of the future may well be companies which help establish better sustainability and financial outcomes at the same time, creating a positive dynamic for investors who increasingly want to be seen as enabling better societal outcomes without missing out on the next big trend, and this is a global opportunity for investors and entrepreneurs, and a key component of this new cooperation paradigm.

In fact a lack of cooperation may be one of the only ways we won't succeed at achieving the necessary transition, and - this can't be stressed strongly enoughnone of this will be possible without economic vibrancy.

India's 2019 economic slowdown and its ongoing low GDP per capita should be especially noted as just one example of the economic imperative behind necessary low-carbon transitions. If India's economy were to thrive, more of its people would insist on positive changes to the often terrible quality of air in its major cities, but for now it cannot, does not and is not able to transition fully and successfully, not until its economy emerges, and certainly many other countries are similarly situated.

We also need governments to create and keep in place the right policies that help support necessary action on lowering carbon emissions. Instead, increasingly nationalist governments are at times being voted into office and are turning away from climate action at the time when it is needed the most. Such voting results have arguably been due to a lack of good jobs and a general 
sense of feeling threatened by modernity, not only as was experienced in recent UK and US elections, but also manifesting at times in otherwise primarily progressive countries, as has been seen with the Gilet Jaunes movement in France, and the ongoing German political dynamic, which threaten to slow their climate responses. This is also important in China, a country which actually does listen to its citizens, and adopts, learns and changes arguably faster than any country in the world (Chap. 8), but China can't act on its own.

The sustainable transition then needs to be explained more clearly as to how it will specifically benefit the average person and their families everywhere versus the alternative, which will be much worse for everyone.

Global education, then, particularly on the benefits of the necessary transition versus what will be economically worse alternatives, is now another essential goal to achieve including in countries such as China and also throughout the West. This kind of discourse is strangely often missing from many global political and media platforms, with several countries and organizations stuck in older ways of thinking and doing business, resisting change or otherwise not taking on the urgency of issues such as climate change, and as a result not enough people see the need to act rapidly.

China can get this right, and quickly given the chance, but it will need cooperation to do so.

It is essential to understand that China will only accelerate on the necessary transition if it itself is economically vibrant; otherwise things will not move forward at the pace that is globally required.

Harvard Business School's case studies are rife with examples of companies which innovated well but didn't combine that with a necessary successful business model to achieve scaled implementation of related solutions, such as battery storage company A123 Systems failed to achieve (Vietor 2011).

Similarly, countries won't have the financial well-being to fully transform without economic vibrancy, and the sort of conditions which allow for investing with confidence at necessary scale.

In fact, China, in response to the economic pressures it is facing, exacerbated as they are by the recent trade war, combined with lessening climate action commitments of countries such as the US, has slowed their own recent progress on climate change in some ways (Wall Street Journal 2019). Without an all-in approach across major countries, adequate and necessary action is likely to lag behind what is required. 
China as a case study of transition success could help transform Asia's other economies, providing an example others can learn from. It is also our contention that if one has concerns about any of China's behavior, more success at driving positive change will come by welcoming China into a community of cooperative nations, and even better, becoming an ongoing investor who can make reasonable demands for one's capital rather than by isolating China and making it defensive and more likely to generate worse reactions internally.

Trapped by existing debt, China in fact now essentially requires foreign capital to enable its own sustainable transition, creating an important vector for positive change through the parallel establishment of minimum standards such as those that the NY State Common Retirement Fund has committed to developing recently. ESG (environmental, social and governance) covenants on investment can relate to minimum standards as part of increasing methods for performing reliable and thorough due diligence across asset class.

In this way, developed country investors can help China's transition, and once it is successful, other developing countries can then also transition, learning from the China example, allowing them to compete, innovate and thrive as well.

There is almost certainly no other way out of the climate crisis in front of us, and in the chapters, recommendations and case studies to follow we will suggest best ways forward for investors and others interested in solving these challenges of our time.

First of all, it's important to truly understand China, all too often misunderstood from a distance.

It's important to understand China's 5000-plus-year history, and while there is endless detail that can be covered on this, we will give the reader a perspective on how China's thinking and ethos have come to be what it is, and will discuss how there is much that makes a lot more sense once you take a walk in China's shoes.

Something that is generally not recognized is that China has not typically started or participated in world wars, has not done so for a long time and doesn't appear to have particular ambition in this regard, but does understandably demand respect. China has long wanted to protect its borders and its sovereignty and to keep from falling into the type of chaos the country has experienced many times throughout its history. Not long ago it was significantly affected by outside forces (Chap. 6) and the Great Wall is of course an ancient example.

China does, however, have an innate sociology that builds trusted circles and relationships (Guanxi, see Conclusion) and through gaining trust can come the potential for mutual success, potentially at a very high level, and this is what is needed now at scale to solve societal challenges as well. 
China is also extremely transformative and entrepreneurial and learns quickly when it makes a mistake. If we care to solve climate change, those of us in the West have to be much less locally minded and myopic and think more holistically on a global basis. We all need to recognize that this something of a left brain/right brain thing, whereby Asia is half the possibility, and arguably more than half of the potential from a transformation potential perspective. This is an entrepreneurial moment, and also a moment to involve as many people and countries as possible to successfully and fully transform global society.

This really does need to be an all-in movement, one that leaves no one stone unturned in the search for economic systems which can thrive in what will otherwise be a climate-challenged future. How do we get there?

Let's see if our book can at least help lead the way toward establishing common goals and pathways forward for us to achieve what we need to do together. The West isolating China and making it an enemy only makes this transition harder and less likely to occur, reducing the opportunity for successful global transformation.

This will also require China to continue to learn and adapt to give the West space to operate comfortably in the country, and at the same time for the West to fully understand China. Such a new reality will only benefit China, a country with ambitions and goals and a government that can impose clear long- term plans, and with a current environmental and societal landscape that needs fixing, which the Chinese people themselves increasingly want to see achieved. Fortunately, no other country gets on with implementing plans once it sets its mind to it in the way that China can.

We now look at the challenges China faces, its history, its ambition and ethos, its desire to innovate and thrive, and perhaps through aiding this necessary transition and helping to lead the global response to climate change, China can gain the respect it arguably deserves.

The time to come together and cooperate for global success is now, and we likely won't get another chance.

\section{References}

Axios. 2019. Inside John Kerry's Shadow Diplomacy on Climate Change. https://www. axios.com/john-kerry-vietnam-diplomacy-climate-change-5912b5f6-27aa-474bb129-56180427f821.html. Accessed 4 Jan 2020.

China Daily. 2017. China Has the World's Largest Middle Class Population. https:// www.chinadaily.com.cn/a/201712/21/WS5a3b15aea31008cf16da292f.html. Accessed 4 Jan 2020. 
Dalio, Ray. 2019. Looking Back on the Last 40 Years of Reforms in China. https:// www.linkedin.com/pulse/looking-back-last-40-years-reforms-china-ray-dalio/. Accessed 5 Feb 2020.

Financial Times. 2019. The Asian Century Is Set to Begin. https://www.ft.com/ content/520cb6f6-2958-11e9-a5ab-ff8ef2b976c7. Accessed 4 Jan 2020.

IPCC. 2014. AR5 Climate Change 2014, Mitigation of Climate Change. https:// www.ipcc.ch/report/ar5/wg3/. Accessed 4 Jan 2020

Krosinsky, Cary, Nick Robins, et al. 2008. Sustainable Investment: The Art of Long Term Performance. London: Earthscan.

Krosinsky, Cary, Todd Cort, et al. 2018. Sustainable Innovation and Impact. Abingdon/ New York: Routledge.

Nordhaus, William. 2015. Climate Clubs: Overcoming Free-Riding in International Climate Policy. American Economic Review. https://www.aeaweb.org/articles? id $=10.1257 /$ aer. 15000001

Reuters. 2019. Scientists Urge Stronger Paris Agreement Pledges to Curb Climate Change. https://www.reuters.com/article/us-un-climatechange-targets/scientistsurge-stronger-paris-agreement-pledges-to-curb-climate-changeidUSKBN1XF26I. Accessed 4 Jan 2020.

South China Morning Post. 2018. How Trade Links Between Southeast Asia and China Have Thrived for More Than 1,000 Years. https://www.scmp.com/ presented/news/asia/topics/china-and-southeast-asia/article/2158635/how-tradelinks-between. Accessed 4 Jan 2020.

Stanford Woods Institute for the Environment. 2019. Global Carbon Emissions Growth Slows, but Hits Record High. https://news.stanford.edu/2019/12/03/ global-carbon-emission-increase/. Accessed 4 Jan 2020.

UNCTAD. 2019. World Economic Situations and Prospects. https:/unctad.org/en/ PublicationsLibrary/wesp2019_en.pdf. Accessed 4 Jan 2010.

US Energy Information Administration. 2016. https://www.eia.gov/todayinenergy/ detail.php?id=26252. Accessed 4 Jan 2020.

US-ASEAN Business Council. 2019. Growth Projections. https://www.usasean.org/ why-asean/growth. Accessed 4 Jan 2020.

Vietor, Richard. 2011. A123 Systems. Harvard Business School.

Wall Street Journal. 2019. In Tougher Times, China Falls Back on Coal. https:// www.wsj.com/articles/in-tougher-times-china-falls-back-on-coal11577115096?shareToken=st30cc41c3c455426e858c327498b273b8\&reflink= share_mobilewebshare. Accessed 4 Jan 2020.

World Bank. 2018. World Development Indicators. https://data.worldbank.org/ indicator/NY.GDP.MKTP.CD?year_high_desc=true. Accessed 4 Jan 2010.

Yale College. Secretary John Kerry's Visit to the Exit Seminar of the Energy Studies Multi-Disciplinary Academic Program (MAP) of April 2019. 